\title{
The 22nd European Conference on Biomaterials: retrospective view, facts and figures
}

\author{
Christine Wandrey • Marc Bohner • \\ Geoff Richards
}

Published online: 12 December 2009

(C) Springer Science+Business Media, LLC 2009

The Swiss Society for Biomaterials (SSB) has hosted the 22nd European Conference on Biomaterials-ESB 2009 from September 7 to September 11, 2009, in the Beaulieu Convention Center Lausanne. The ESB conferences are the annual conferences of the European Society for Biomaterials (ESB) taking place the three years between two World Biomaterials Congresses.

1044 regular abstracts +23 last minute abstracts were submitted for presentation at ESB 2009 exceeding by far the submissions to previous European Biomaterials Conferences. After rigorous reviewing and invitation, the conference program finally was composed of 10 plenary lectures, 4 award lectures (Jean Leray and George Winter, both for 2008 and 2009), 26 keynote lectures, of these half invited and half selected following the recommendations of the abstract reviewers, 156 regular talks, and 630 posters. Figure 1 shows the thematic allocation of all submitted abstracts, oral and posters, to the master keywords of the conference. From this figure becomes obvious that the trends and topics analyzed after the World Biomaterials Congress 2008 principally continued for the ESB 2009 [1].

ESB 2009 had a very impressive scientific program with world-renowned plenary speakers and presenters. Posters were seen as an indispensable part of the ESB 2009. Therefore, all posters were visible on all four days of the

C. Wandrey $(\square)$

Ecole Polytechnique Fédérale de Lausanne,

Lausanne, Switzerland

e-mail: christine.wandrey@epfl.ch

M. Bohner

RMS Foundation, Bettlach, Switzerland

G. Richards

AO Research Institute, Davos, Switzerland
ESB 2009. The poster sessions, all breaks and special events provided excellent opportunities for in-depth discussions, to gain new international contacts for future collaborations, and to exchange ideas.

1201 attendees from 44 countries coming from all continents participated in the ESB 2009, a number slightly higher than at ESB 2005 in Sorrento, Italy. Figure 2 provides some details of the attendance. The graph identifies Switzerland, UK, Germany, Spain, Italy, and France as the countries with the highest number of participants. However, also the attendance from the oversea countries Japan, USA, Brazil, and Australia was good.

ESB 2009's concept of dedicating one of the five parallel session lines throughout the day to a "Theme of the Day" found wide acceptance. Each conference day started with an ESB award lecture followed by a plenary lecture on clinical problems within a "Theme of the Day" as well as a plenary lecture of the state of the art in research of that area. Particular highlights of the ESB 2009 were the plenary lectures of the opening and closing ceremonies presented by Prof. Jeffrey A. Hubbell, Switzerland, and Prof. Buddy D. Ratner, USA. Pre-meeting and during meeting workshops, which were mainly educational completed the scientific program.

In addition to the "Theme of the Day", ESB 2009 has initiated accreditation by the European Accreditation Council for Continuing Medical Education (EACCME) to provide CME credits. The Schweizerische Gesellschaft für Orthopädische Chirurgie (SCO) allocated 25 points. The European Orthopedic Research Society (EORS) was brought as a new sister society to the ESB while the connections to current ESB sister societies were re-strengthened by incorporation of special sessions into the program. ESB 2009 further strengthened the scientific basis of the traditional ESB core topics while encouraging the 


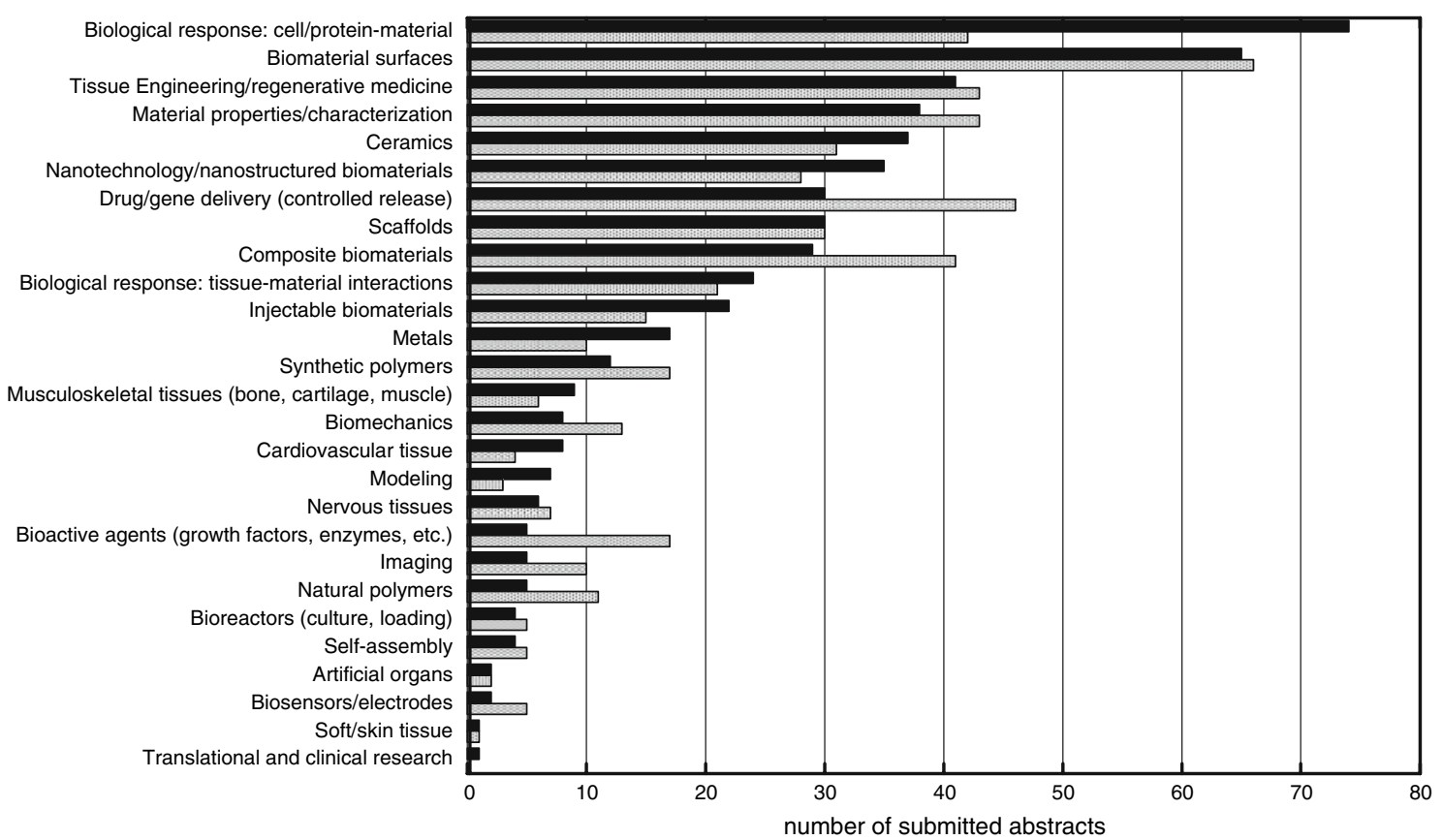

Fig. 1 Thematic abstract submission (master keywords) before evaluation. Black abstracts submitted to be considered as oral contribution, grey abstracts submitted for posters

Fig. 2 Attendance at ESB 2009

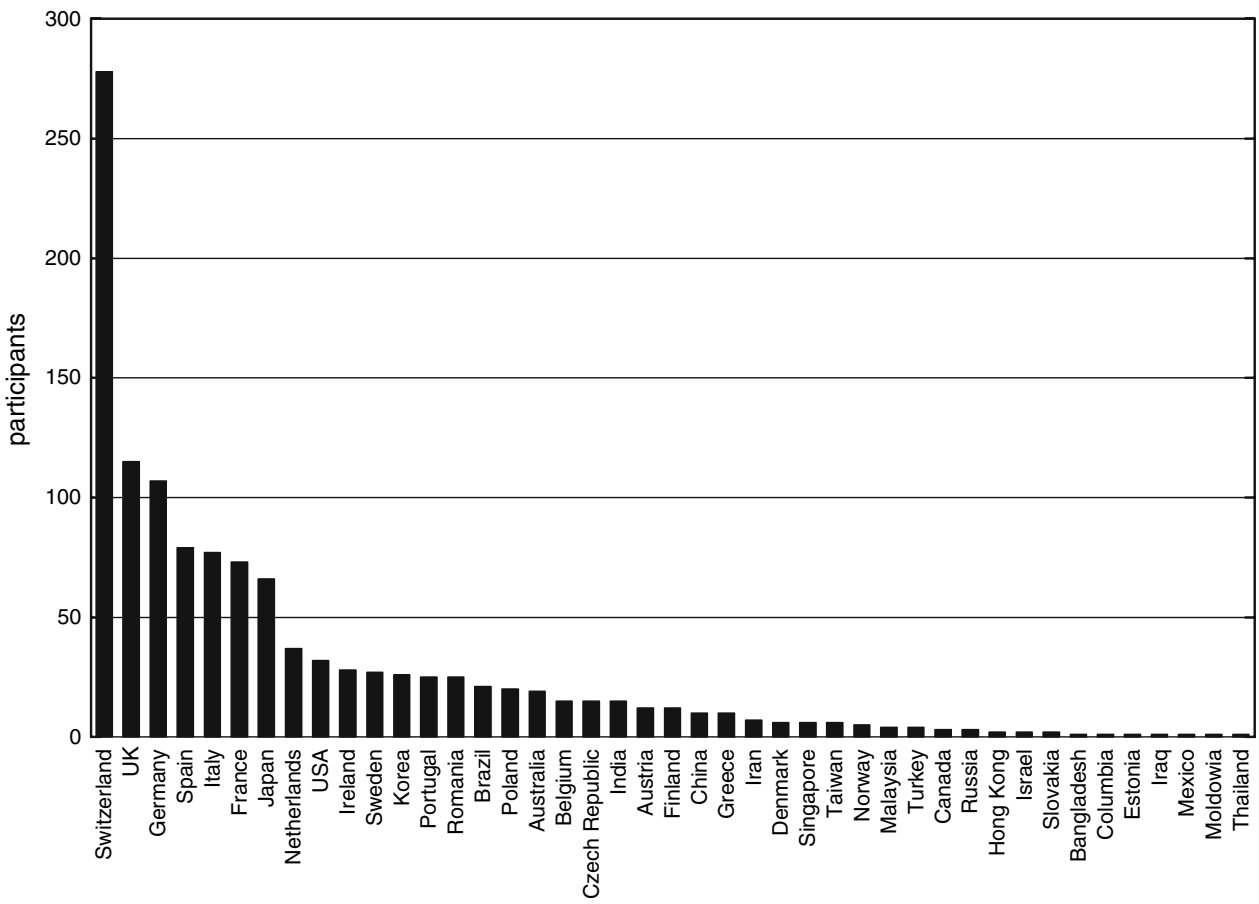

interaction with both the clinical and industrial side of biomaterials. ESB 2009 has drawn on the extensive MedTech industry within Switzerland to bring closer working relationships with industry. More than 20 companies were present with an exhibition booth and a special exhibitor evening took place at the "Industrial Day".
ESB 2009 has also introduced conflict of interest statements (Compulsory Presentation Statements) to let ESB 2009 participants better interpret posters and talks declaring any potential conflict of interest that presenters might have with the presented data. This will need more enforcement for future meetings, as this was a partial success. 
ESB 2009 succeeded to connect biomaterial research with current clinical problems to produce progressive translational research and was the venue to present and discuss basic, applied/translational and clinical research in a multi-disciplinary environment. This special issue of JMSMM is a collection of invited contributions proposed by reviewers during the reviewing and selection process.

The organizers again thank all institutions, organizations, and companies that have supported ESB 2009 and also recognize the efforts of all committee members and reviewers who have helped to organize the scientific program, workshops, forums, exhibition and special events. However, finally, the activities of the participants made the ESB 2009 a very successful and rewarding meeting.

\section{Reference}

1. Leeuwenburgh SCG, et al. Trends in biomaterials research: an analysis of the scientific programme of the World Biomaterials Congress 2008. Biomaterials. 2008;29:3047-52. 